\title{
Exploring of Education Equity Mechanism Based on the Concept of Coordinated Development
}

\author{
Wang Hui
}

College of Politics and Sociology, Xianyang Normal University, Xianyang, Shaanxi, 712000

Key words: equality; coordination; education; mechanism

\begin{abstract}
Educational Equity is the foundation of Chinese dream realization. This paper analyzes practical difficulties and reasons of equity of our countries' educational opportunities, procedures and effectiveness, trying to promote education equity from mechanism construction of coordination with economic, balancing various relationships and designing development of differences dislocation and other aspects, based on the concept of “Coordinated Development” put forward by the Fifth Plenary Session of the Eighteenth. "Learning to teach" from ancient times has been mentioned by people, while in the new period of social development in China, this view has been given a new connotation. Whether education is coordinated or not, the realization of the dream of "education fairness" is directly related to the degree of realization of teaching. The Fifth Plenary Session of the Eighteenth of the Communist Party of China (CPC) pointed out that it isnecessary to establish the development concept of innovation, coordination, green, openness and sharing, and to clarify the inherent requirement of sustained and healthy development. For the rapid expansion of education has experienced, to sustained and healthy development, it is necessary to establish a coordinated development concept and to promote fair education. It can be said that based on the concept of coordinated development that explore the educational equity mechanism has a huge boost for the new target "modernization of education to make new progress, the working age of the population has significantly increased the number of years of education".
\end{abstract}

\section{The connotation of educational fairness and coordinated development of education}

Since the 18th National Congress of the Communist Party of China (CPC), the general dream proposed by General Secretary Xi Jinping has become a hot topic of the people and the realization of the great rejuvenation of the Chinese nation. The specific goal of education is "Learning to teach", that is, the education fairness. In the past few years, the state has also taken measures to increase investment, increase poverty alleviation to solve the obstacles to the realization of the dream of education. Minister Yuan Guiren at the 12th National People's Congress meeting said that the "fairness of education was the best thing in five years". However, only the increase in investment is only a dimension of educational equity, it is an important part of the content. China as 
a country with a lot of population in the world, there is a certain gap in the allocation of educational resources, people's education conditions, etc.to realize education dream.

In social equity, educational equity is the basis of fairness and is the basis for guiding other social equity. The discussion of education fairness mainly focuses on the aspects of "educational fair society", "equal opportunity of education", "class game theory" and "educational fair difference theory" [1], and so on, mainly from the multi-disciplinary aspects. Generalized educational equity is fairness in law, education policy, educational activities and practical educational activities and real education. It is a way for everyone to enjoy equal education, equal access to public education resources. [2]

In educational activities, education fairness is a kind of subjective experience, social system, realistic state and ideal pursuit which are unique to human society about equality of educational opportunity and rational distribution of educational rights and educational resources. [3] First, the fairness of the opportunities and rights of education, which determines the fairness of the process and effect. Second, the fairness of education object and subject, reflecting the fair allocation of various resources to provide fair opportunities for development, etc., so educators have basic equal rights to get basic equal education. Third, the need to achieve the ultimate results of fairness is a good way to achieve equal and effective educational results.

Ancient people put forward the "doctrine of the mean", "Heaven and Man" and the West "Survival of the Fittest" and other theories, which are the most coordinated development of man and nature of the performance. "Sustainable development" and "balanced development" and other theories are the best performance for the coordinated development of the economy.

For education, coordinated development has become an urgent problem to be solved, the state has also attached great importance to the coordinated development of education. The coordinated development of education is composed of two aspects of external coordination and internal self-coordination. It is the state of the factors that make up the changes in the development of education, the organic unity of the structure and the state of benign interaction with the external environment. Education development embodies the unity of purpose and coherence. "[4] On the one hand, educational activities need to be carried out in a good environment, and need to balance with the economic society and so on, to maintain a state of mutual adaptation. On the other hand, the elements of educational development need to unite to support the development of education and activities, to maintain the balance between the elements, and constantly to promote the development of education. 
Due to the unbalanced economic and social development and other reasons, there are still many uncoordinated phenomena in the development of education in our country, which hinders the realization of educational fairness.

The incongruity of education is mainly reflected in the uncoordinated education of urban and rural areas, the uncoordinated development of regional education, the coordination of educational development among schools, and the incongruity between educational groups. [5] First, the development of urban and rural education is not coordinated. Due to the existence of the dual urban structure of urban and rural areas in China, the state has invested more in the development of urban education, less investment in rural areas, especially in remote rural areas, leading to the uncoordinated development of urban and rural education. As in the education of capital investment, in 2000, urban and rural primary school students per capita funding were 1492.1 yuan and 476.1 yuan, junior high school students per capita funding were 2671.2 yuan and 861.6 yuan. In the faculty of the equipment, the rural areas for a long period of time to private teachers, less than $60 \%$ of public teachers, and even private teachers cannot meet the needs of the qualifications. There is even greater gap between Beijing, Shanghai high school teacher qualifications. The rate reached 91.2\% and 95.6\% respectively, while the Gansu and Qinghai rural schools and other provinces of the pass rate of less than 70\%. [6] A In the case of colleges and universities, the quantity and quality of the colleges and universities in the eastern developed areas are obviously higher than those in the western underdeveloped areas. In 1867 colleges and universities in the middle of 8867 in 2006, only 368 in the west and 70,000 in the east. 105 million people have a university. [7] Third, the development of education between schools is not harmonious. In the same city or region, due to the existence of factors such as policy orientation, there are some priorities and non-focus, the support and tilt there is a big gap. Such as the existence of "211" and "985" distinction between colleges and universities.

\section{Realistic dilemma of educational fairness}

China's education in the early 21st century goes into the popular stage, it can be said that it enters the post-education stage of popularization now. The rapid expansion of the scale of pre-education, making all levels of education prosperity. However, while paying attention to the scale of expansion, there is no emphasis on the fair and coordinated development of education. The practical dilemma of educational fairness is mainly manifested in the following aspects.

On the one hand, the opportunities for providing education are different. Due to the uncoordinated development of education, there are differences in the educational effects of different educational types. On the other hand, the incompatibility of educational development leads to 
differences in the quality of educational activities, and the conditions and opportunities for educators are not the same.

Similarly, due to the uncoordinated development of education, there are some unfair practices in the process of education. First, the performance of education in the process of development. The state has gradually reached four percent of the gross national product, but in the implementation process, because of the different regions, there is a greater gap between urban and rural investment, leading to unbalance development. For basic education, students are required to go to school in the nearest school district, and there is a difference between the focus and non-priority quality and general teaching resources in each school district, which indirectly leads to the disagreement of educational opportunities. Second, the disparity in the allocation of educational resources, uneven inequality led to the education process. Regional economic and social development is not coordinated, the input is not balanced, making the educational conditions and the level of education, quality and so on are not coordinated, affecting the implementation of the education process.

The injustice of the effect is mainly manifested in the unfairness of the role and extent of education to people, and the most important reason is the uncoordinated urban and rural areas such as educational development. China's rural areas, especially in the western remote rural areas, due to the low quality of teachers, lack of serious shortage of inputs and other reasons, basic education investment and quality is generally lower than the city, leading to the effectiveness of education and quality far lower than the city. [8]

\section{The realization of educational equity requires the coordinated development of education}

The fairness of education is not a fairness of a single process, is not a fairness involving a single content, but a comprehensive coordination system involving economic, political, social and cultural aspects. It is a systematic process that requires the coordination of social ideology balance of urban and rural regional development, coordination of economic input and capacity equality, coordination of education effectiveness of the fairness. Only through coordinated development, education can be achieved gradually.

The coordinated development of education is an objective requirement to realize the fairness of education. The coordinated development of education is embodied in economic, social and political aspects. Education is "to meet the requirements of social and economic development, for the development of social and economic development, full, applicable, diverse, excellent talent, and for the future social and economic development talent pool." [9]

The coordinated development of education is a concrete requirement embodied in various elements. Promoting the coordinated development of urban and rural education, regional education 
coordinated development, coordinated development of different levels of education is the main aspect. The coordinated development of urban and rural education needs to change the dual mechanism of urban and rural areas in China, to seek a complementary mechanism for urban and rural development, to completely change the reality of urban and rural education development is not balanced, to achieve equal access to educational opportunities. Regional education needs to develop a balanced development according to the regional economic and social development of reality and characteristics, change the uneven development of different regions of the phenomenon of education. At the same time, we can learn from some of the practices of developed countries, and gradually promote the coordination of different types of education, to build a comprehensive and equitable education development system. The coordinated development of education is also the contradiction and problems of scale, quantity and quality.

China is a populous country, the need for education is gradually expanding, but also gradually diversified. This process requires the education of fairness, fair education needs to coordinate the development of coordinated development is to narrow the gap. And narrow the gap is not stereotyped. To achieve the coordinated development of education, at this stage we should highlight their own characteristics, to find suitable for their own characteristics of the development path and direction, to do the dislocation of development, the characteristics of education, to highlight the characteristics of education. For the development of educational differentiation is mainly reflected in the regional differences, different levels and different aspects of the category. China is a country with great land, and the reality and trend of economic and social development in different regions are different. As an intellectual support for economic and social development, education needs to reflect the characteristics of the region and need to provide different educational resources for all. The difference in the level of dislocation is mainly reflected in the difference in the process of education.

China's education for the social and economic development services, by the national policy-oriented greater impact, in general, are based on the national system design and construction. With the passage of time, the economic and social development, the system for the development of education needs to be constantly adjusted to better promote the education fair and the effect of improvement. The reform of the education system includes the reform of the internal system of education and the reform of the supporting system. The reform of the internal system is a complex system, including the examination system, learning system, education system, evaluation system, including a variety of systems. The reform of these systems requires a systematic analysis, a comprehensive trade-off and a gradual reform. The supporting system mainly includes the financial investment system, the resource allocation system and some system of guaranteeing the education 
fairness. The reform of these systems requires scientific innovation and change in accordance with the trends and needs of educational reform and development. The fairness of the system design is also changing and needs to constantly improve the sound, correct the direction of fairness.

\section{Acknowledgment}

Fund Project: Xianyang Normal University Research Fund Project (16XSYK030).

\section{Reference}

[1] Zhao Hang. Education Fair Connotation Summary [J]. Contemporary Education Practice and Teaching Research, 2016 (1): 202.

[2] Shi Zhongying. The Main Connotation and Social Significance of Educational Fairness [J]. Journal of China Education, 2008 (3): 1-2.

[3] Ye Zongbo, Tang Rongcheng.Study on the Interactive Relationship between Educational Fairness and Harmonious Society [J]. Academic Forum, 2005, (8): 193.

[4] Sang Jinlong. "Education Collaborative Development" Connotation [J]. Journal of Education, 2010 (2): 30.

[5] Chen $\mathrm{Wu}$, Liu Chunyang. Educational Disharmony of the Main Performance and Countermeasures [J]. Journal of Hunan Agricultural University (Social Science Edition), 2008 (5): 12.

[6] Liu Huaijie. Dual Social Structure under the Coordinated Development of Urban and Rural Education and Countermeasures [J].Technology and Higher Education Research, 2006 (4): 17-18.

[7] CaiWenbo, Li Xiaojuan.Study on the Coordinated Development of Higher Education in the East and the West and Its Countermeasures [J]. Journal of Shihezi University (Philosophy and Social Sciences Edition), 2009 [3]: 82.

[8] Liu Haimin, DuanLihua. Educational Equity: Dual Measurement of Quality and Quantity of Educational Development [J]. Journal of Northeast Normal University (Philosophy and Social Sciences), 2002, (5): 108-109.

[9] Zhu Yongxin. Education Focus on the Development of Key Areas, Aspects and Objects [N]. Science Times, 2009-02-06. 